\title{
Electrospray deposition in vacuum as method to create functionally active protein immobilization on polymeric substrates
}

\author{
Enzo Fornari ${ }^{a}$, Clive J. Roberts ${ }^{a}$, Robert H. Temperton ${ }^{b}$, James N. O'Shea ${ }^{b}$ \\ a Laboratory of Biophysics and Surface Analysis, School of Pharmacy, The University of Nottingham, Nottingham \\ NG7 2RD, UK \\ ${ }^{\mathrm{b}}$ School of Physics and Astronomy and Nottingham Nanotechnology and Nanoscience Centre (NNNC), \\ University of Nottingham, Nottingham NG7 2RD, UK
}

\begin{abstract}
We demonstrate in this work the deposition of a large biological molecule (fibronectin) on polymeric substrates in a high vacuum environment using an electrospray deposition system. Fibronectin was deposited and its distribution and structure investigated and retention of function (ability to promote cell adhesion) on return to liquid environment is shown. AFM was used to monitor changes in the morphology of the surface before and after fibronectin deposition, whilst the biological activity of the deposited protein is assessed through a quantitative analysis of the biomolecular adhesion and migration of fibroblast cells to the modified surfaces. For the first time we have demonstrated that using high vacuum electrospray deposition it is possible to deposit large protein molecules on polymeric surfaces whilst maintaining the protein activity. The deposition of biological molecules such as proteins with the retention of their activity onto clean well-controlled surfaces under vacuum condition, offers the possibility for future studies utilizing high resolution vacuum based techniques at the atomic and molecular scale providing a greater understanding of protein-surface interface behaviour of relevance to a wide range of applications such as in sensors, diagnostics and tissue engineering.
\end{abstract}

\section{Introduction}

The ability to create functional scaffolds with the capacity to support cell adhesion, growth and migration, for applications in tissue engineering requires scaffolds with specific characteristics. The correct microstructure [1] and porosity [2] of the scaffolds and the right 
biochemical microenvironment play an essential role in the promotion of cell adhesion, cell viability and migration. The use of extra cellular membrane proteins and cell surface markers to facilitate cell adhesion and migration on substrates such as fibronectin, has been extensively studied. $[3,4]$.

Fibronectin (FN) is a large dimeric glycoprotein, $450 \mathrm{kDa}$ in size, found in both blood plasma and extracellular matrix. It binds various molecules at specific binding sites located on distinct fragments or modules of the protein. Among these is a large central cell-binding domain (CCBD) that contains a motif recognized by many integrins: the amino acid sequence Arg-Gly-Asp (RGD) in the FNIII10; the recognition depending on the conformations of both integrin and FN [5]. The ability of fibronectin to change its native conformation when absorbed on a substrate, influencing the cell adhesion and spreading $[6,7]$ through changes in the cytoskeletal organization, has been identified as an important consideration in the design of biomaterial substrates for tissue engineering and biotechnology applications.

Many studies have been performed concerning the spatial bio-functionalisation of surfaces by adhesion of ECM proteins such as fibronectin, laminin and collagen $[8,9]$ using traditional and soft lithography techniques (micro contact printing and self-assembled monolayers), with the creation of defined protein micro patterns on surfaces. The deposition of biomolecules directly on substrates for use in cell patterning can also be achieved using electrospray techniques $[10,11]$. Such substrates have demonstrated biomolecular deposition with a resolution close to critical cellular dimension. The ability of electrospray techniques to functionalise surfaces with organic and biological molecules is potentially of fundamental importance in molecular nanotechnology, opening up new opportunities ranging from molecular electronics [12] to specific biological recognition and sensor applications [13].

Electrospray ionisation, a technique most commonly used in mass spectrometry $[14,15]$ to create gas phase ions of large molecules such as polymers and proteins, involves passing a 
solution of the molecule of interest through an emitter (often a metal capillary with OD $<1$ $\mathrm{mm}$ ) held at a high voltage (typically a few kilovolts). At the emitter tip, the large electric field causes polarisation of the solvent and the formation of a Taylor cone. At the tip of the Taylor cone there is an instability, and if the field is sufficiently large a jet of liquid is emitted which breaks up into droplets due to the repulsion of ions at the liquid-air interface. These droplets travel towards a grounded counter-electrode meanwhile solvent is evaporating from the drops. As the drop size reduces, the repulsive effects of the ions become greater and these overcome the effect of surface tension causing the drop to split (a process called Coulomb fission). The processes of solvent evaporation and Coulomb explosion cause the droplets to desolvate producing a plume of molecular ions. Aside from mass spectroscopy, electrospray has been used for the atomization and the surface deposition of a wide range of materials including DNA, [16] biocompatible polymers, $[17,18]$ polysaccharides, and a range of proteins $[19,20]$ with retention of structure and function. Previously most work concerning protein deposition on materials has been performed under ambient conditions. However, Rauschenbach and co-workers [21] reported the deposition of the protein bovine serum albumin on graphite surfaces analysed ex situ by atomic force microscopy, and more recently the deposition of folded cytochrome $C$ proteins imaged by scanning tunnelling microscopy [22].

The potential advantages of depositing biological molecules such as proteins with the retention of their activity onto surface held under high vacuum or ultra-high vacuum (UHV) are potentially substantial. The UHV environment allows the preparation of clean surfaces prior to deposition and the in-situ application of high resolution scanning probe microscopy, electron spectroscopy and X-ray absorption techniques to understand interactions at the atomic and molecular scale. The combination of such techniques with UHV-compatible electrospray deposition has successfully been applied by the authors to the deposition of complex, fragile and non-volatile molecules on surfaces prepared in UHV including giant porphyrin nanorings, [23] single molecule magnets [24] and organometallic dye molecules [25]. Whilst these studies demonstrated the intact deposition of these complex molecules 
with retention of their chemical, electrical and magnetic properties the question remains if proteins deposited in this manner in vacuum retain their biological activity when returned to liquid environments of relevance to their application in a wide range of fields such as sensors, diagnostics and tissue engineering.
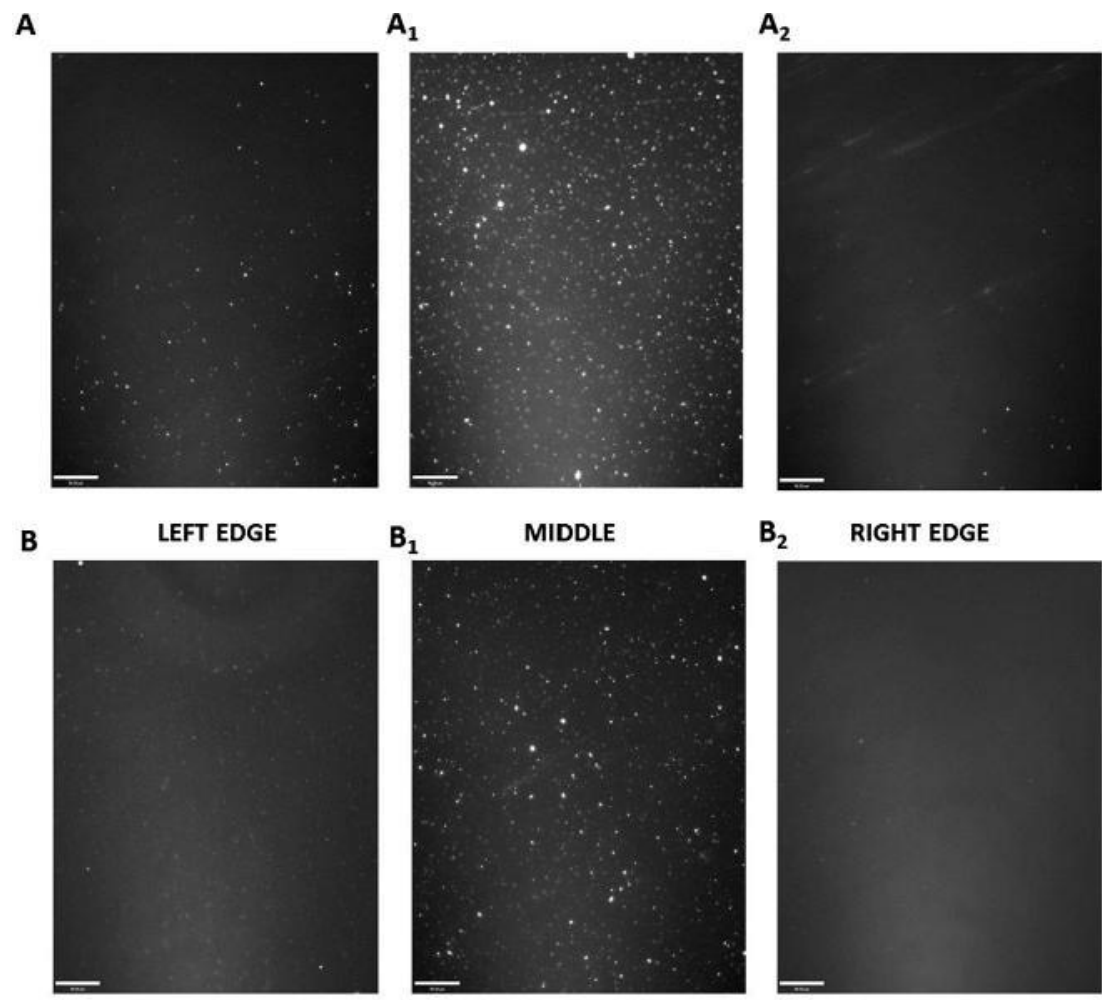

$B_{2} \quad$ RIGHT EDGE

C
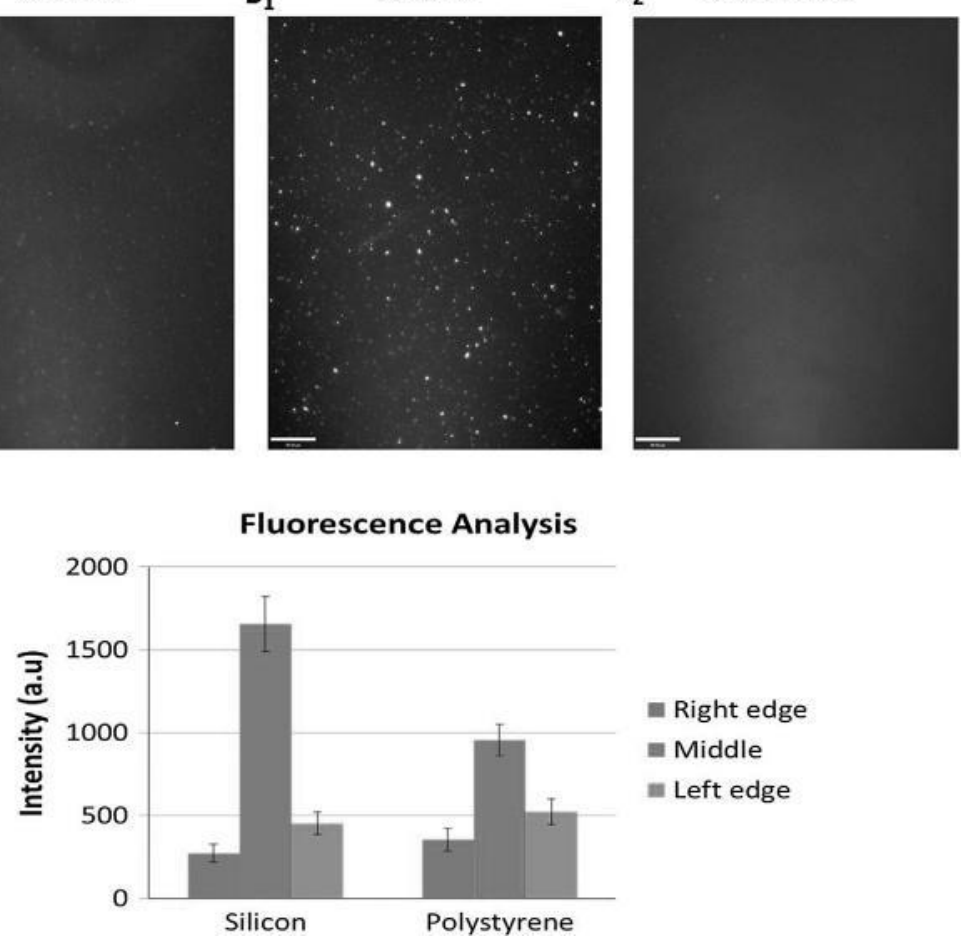

Fig. 1. Fluorescence images of the silica $(A 1, A 2, A 3)$ and non-TCP polystyrene (B1, B2, B3) substrates after Fibronectin deposition (Scale bar $90 \mathrm{Lm}$ ), and an analysis of the relative fluorescence intensity (C) (mean \pm SD) reported $(400 \times 400 \mathrm{DPI})$. 
A

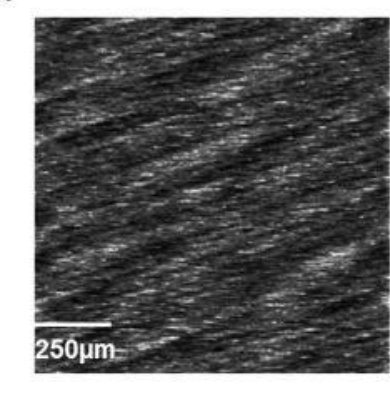

B



C

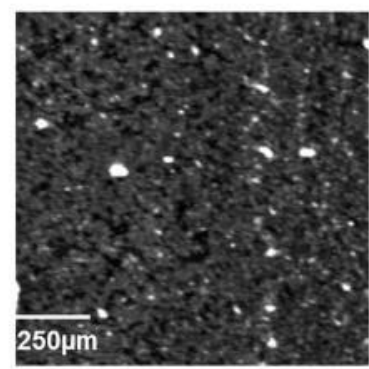

$0.6 \mathrm{~nm}$

$A_{1}$

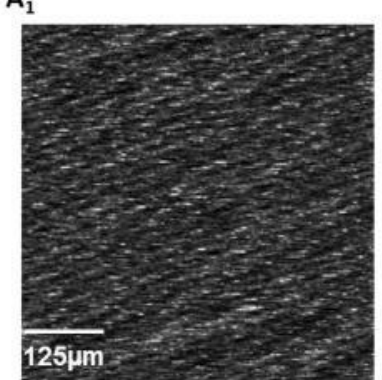

$3.2 \mathrm{~nm}$

$\mathrm{B}_{1}$

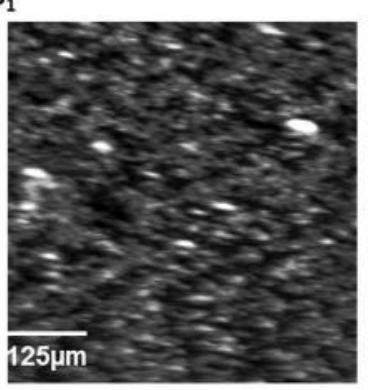

$\mathrm{C}_{1}$

$1.8 \mathrm{~nm}$

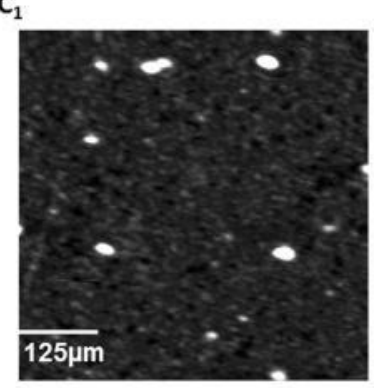

$0.3 \mathrm{~nm}$

$2.6 \mathrm{~nm}$

$1.6 \mathrm{~nm}$

Fig. 2. Representative $A F M$ images recorded on silicon substrate, showing bare substrate $(A, A 1)$, higher protein deposition (B, B1) and lower deposition (C, C1) (400 x 400 DPI).

Table 1. AFM images analysis before and after fibronectin deposition on silicon and non-TCP substrates (mean $\pm S D$ ).

\begin{tabular}{|l|l|l|l|}
\hline Silicon & Bare substrate & High FN (centre) & Low FN (outsides) \\
\hline Roughness & $0.35 \mathrm{~nm} \pm 0.1 \mathrm{~nm}$ & $1.7 \mathrm{~nm} \pm 0.2 \mathrm{~nm}$ & $0.65 \mathrm{~nm} \pm 0.12 \mathrm{~nm}$ \\
\hline Particle size & $/$ & $31.52 \mathrm{~nm} \pm 3.2 \mathrm{~nm}$ & $28.2 \mathrm{~nm} \pm 2.7 \mathrm{~nm}$ \\
\hline Surface coverage & $/$ & $78 \%$ & $32 \%$ \\
\hline Non-TCP & & & \\
\hline Roughness & $2.9 \mathrm{~nm} \pm 0.5 \mathrm{~nm}$ & $3.5 \mathrm{~nm} \pm 0.3 \mathrm{~nm}$ & $1.8 \pm 0.2 \mathrm{~nm}$ \\
\hline
\end{tabular}


In this work in order to perform deposition experiments with large organic and biological molecules on polymeric substrates using a high vacuum electrospray deposition system, fibronectin was deposited and its distribution, structure and function (retention cell-binding activity), when in a relevant liquid environment was investigated. AFM was used to monitor changes in the morphology of the surface before and after fibronectin deposition, whilst the biological activity of the deposited protein is assessed through a quantitative analysis of the biomolecular adhesion and migration of fibroblast cells to the modified surfaces. For the first time we have demonstrated that using high vacuum electrospray deposition it is possible to deposit large protein molecules on polymeric surfaces whilst maintaining the protein activity when returned to a liquid environment.
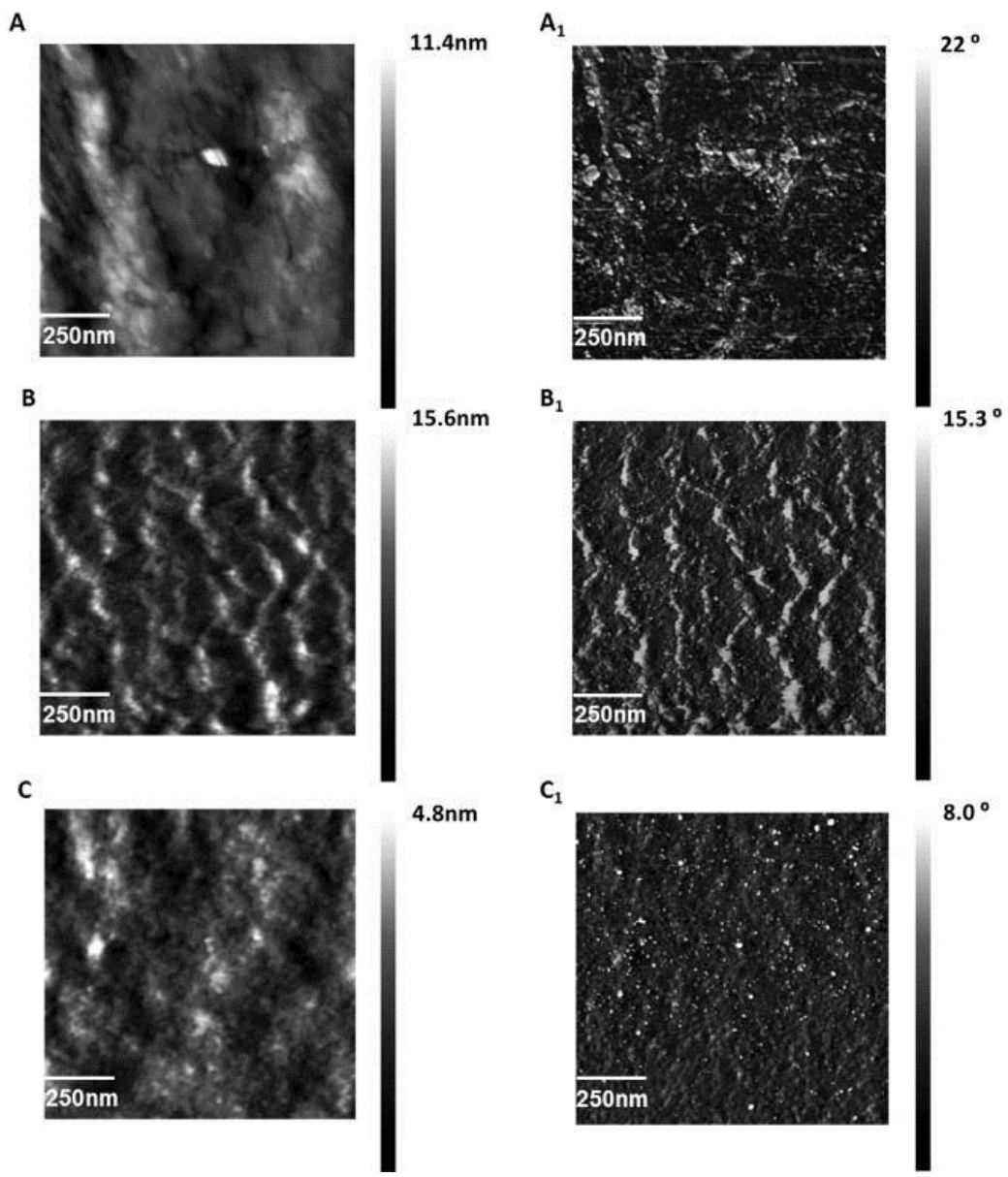

Fig. 3. Representative AFM images recorded on not-TCP substrate, showing bare substrate (A), higher protein deposition (B) and lower deposition (C). In figures ${ }_{\mathrm{A} 1}, \mathrm{~B} 1$ and $\mathrm{C} 1$ phase images are reported $(400 \times 400 \mathrm{DPI})$. 


\section{Experimental session 2.1. Materials and methods}

\subsubsection{Chemical compounds}

Silicon wafers (p-type, 100 orientations), were obtained from Compart-TechMagnus, Tamworth, U.K. Pluronic F127, rhodamine-labelled fibronectin (MW 450 kDa), phosphate buffer pH 7.4, DMEM media, FCS, PBS, non-TCP (polystyrene plastic plates) were obtained from Sigma Gillingham, Dorset, UK.

\subsubsection{Instrumental and analytical tools}

AFM DI3000, RTESPA probes Brucker Coventry (UK). Fluorescence microscopy (IRE2) Leica (UK). Nikon Eclipse TS100 Microscope Diagnostic Instruments (UK). Volocity 5.2 software Improvision (UK).

2.1.3. Electrospray methodology and protein deposition on substrates The substrates were placed in the deposition chamber and pumped down over $12-18 \mathrm{~h}$ to a base pressure of $1 \mathrm{x}$ $10^{\sim 7}$ mbar. A Molecularspray (UK) UHV4 electrospray deposition system was used to deposit the protein onto the substrates in high vacuum conditions: The solution of protein was diluted in using HPLC grade methanol (Sigma Aldrich) in 1:1 ratio (by volume) and was fed into the electrospray emitter (stainless steel, ID = 100 micron, OD = 320 micron, by New Objective) at a rate of $0.3 \mathrm{~mL}$ per hr using a syringe pump (World Precision Instruments). A small quantity of the droplets ( $1 \%$ ) produced by the emitter in atmospheric conditions pass through an inlet capillary into a series of differentially pumped vacuum chambers reducing the pressure in the deposition chamber to $<1 \times 10^{6} \mathrm{mbar}$ during deposition. The depositions lasted approximately an hour and were monitored via the fluctuations in the pressure in the deposition chamber using an ion gauge. Reductions in the size of fluctuations was linked to the gradual clogging of the entrance capillary which was flushed through with solvent every 20 mins.

\subsubsection{Substrate functionalization}

To obtain a uniform distribution of fibroblasts on the areas of the substrate exposed to the deposited protein, and to reduce cell adhesion on the non-TCP (not treated tissue culture 
plastic plate), the substrate was coated with Pluronic F127 a surfactant tri-block copolymer to block cell adhesion but not protein deposition. Non-TCP was treated with $3 \%(w / v)$ of Pluronic F127. The procedure used, in brief, was that the non-TCP was first functionalised using Pluronic F127 with a concentration of $3 \%(w / v)$ and left for $24 \mathrm{~h}$ to be absorbed. A solution of fibronectin dissolved in methanol to a final concentration of $10 \mathrm{lg} / \mathrm{mL}$ was sprayed on the functionalised substrate in vacuum for $60 \mathrm{~min}$.

A

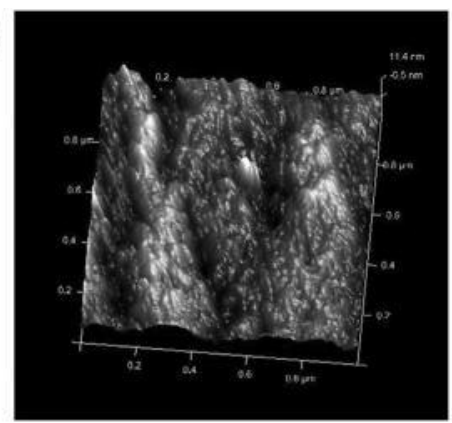

B

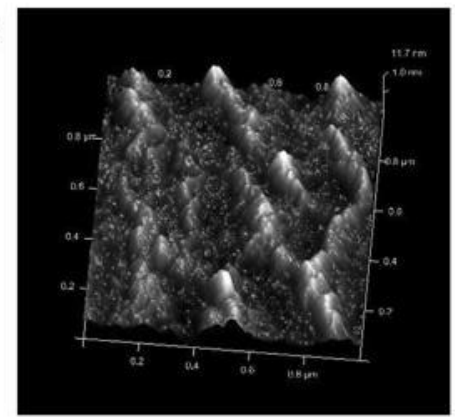

C

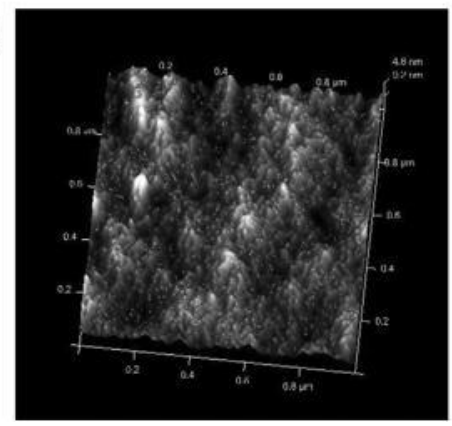

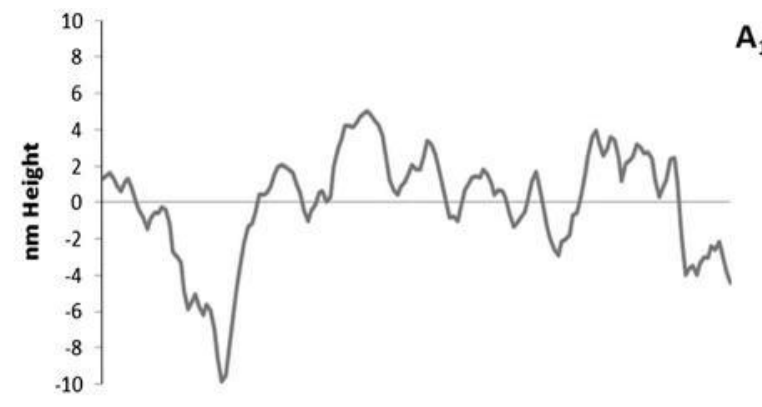



$\mathrm{B}_{1}$
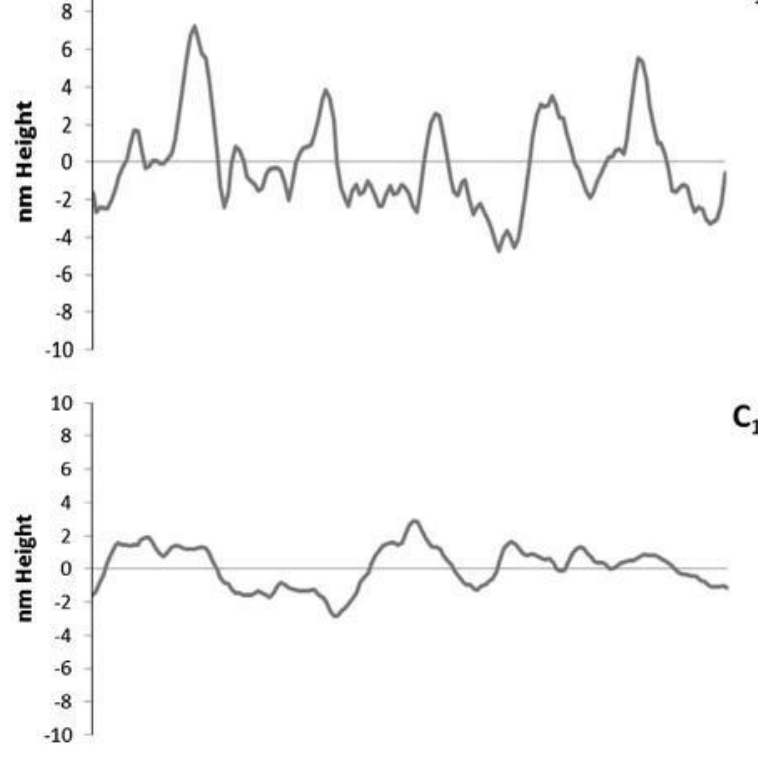

Fig. 4. AFM profile analysis before and after protein immobilization on not-TCP substrate. In figures

A, B, C, 3D images (1 Im scan size) recorded on bare substrate, higher protein density and lower protein density respectively. In figures A1, B1 and C1 the corresponding profile analysis are reported (400 x $400 \mathrm{DPI})$. 


\subsubsection{Cell culture}

NIH-3T3 mouse fibroblasts were grown in Dulbecco's modified Eagle's medium (DMEM) with $10 \%$ FCS and standard additives. Cells were genetically labelled as previously described [26] using transduction of lenti viruses expressing enhanced monomeric red fluorescent protein (mRFP). Cells were selected with Puromycin (NIH-3T3: $3 \mathrm{mg} / \mathrm{mL}$ ) for three passages. Flow cytometric analysis confirmed that cells were $>95 \%$ labelled. For patterning, cell suspensions of $10^{6}$ cells (in $4 \mathrm{~mL}$ per well) were seeded onto non-TCP (previously functionalised with pluronic F127), already functionalised with rhodamine-labelled fibronectin in defined media conditions (lacking FCS). Cells were allowed to attach for a defined period (NIH-3T3, 2 h). Non-adhered cells were removed by gently washing twice with phosphate buffered saline (PBS) and replacing this with fresh growth media.

\subsubsection{Imaging}

Fluorescence microscopy and atomic force microscopy (AFM) were used to monitor property changes before and after protein immobilization. Fluorescence analysis was conducted using a Leica IRE2 microscope with appropriate filtering conditions for rhodamine-labelled fibronectin (535 nm excitation and $585 \mathrm{~nm}$ emission). AFM images were acquired in air in tapping mode using a Bruker D3000 micropscope with RTESPA probes (spring constant $20-80 \mathrm{~N} / \mathrm{m}$, resonant frequency $300-400 \mathrm{kHz}$ ) using different scan sizes and rates. The Nanoscope Analysis program (Bruker, Version 1.20) was used for quantitative analysis of the AFM images. Bright field and fluorescent images of 3 T3 fibroblasts cells were taken using a Nikon Eclipse TS100 Microscope and analysed using Volocity 5.2 software (PerkinElmer).

\subsubsection{Cell migration}

$\mathrm{NIH}-3 \mathrm{~T} 3$ mouse fibroblasts were seeded with a cell density of $10^{6}$ cells (in $4 \mathrm{~mL}$ per well) onto non-TCP (previously functionalised with pluronic F127 and already patterned with fibronectin as described above) and left two hours for adhesion to the substrate. A media lacking in fetal calf serum (FCS) was used to avoid any interaction between the fibronectin 
and the other proteins present in the media. After two hours cells were washed abundantly with PBS and then the media replaced. Time-lapsed fluorescent micrographs images were taken at $24 \mathrm{~h}$, which were subsequently analysed with the Chemotaxis tool (ibidi) for Image J (National Institute of Heath).

\subsubsection{AFM imaging analysis}

Quantitative imaging analysis of the substrates before and after protein immobilization was performed using the Nanoscope Analysis program (Version 1.20). Different scan size images were collected on the substrate before and after protein deposition from $5 \mathrm{tm}$ to $0.5 \mathrm{tm}$ scan size, an example of which is reported in Fig. 2. Quantitative analysis of the surface coverage after protein deposition was performed considering the differences observed between the bare and the functionalised substrate conducting a specific particle analysis with the Nanoscope Analysis programme. For each sample, 10 independent analyses where conducted in different areas ranging from the centre to the edges of the substrate. The analysis of the particle diameters and the surface coverage were represented considering three areas and the average value of the analysis reported in Table 1 . Analysis of the height profile of the surface before and after protein immobilization was performed considering three sections of each area (total of 15 areas analysed) and an average value of the roughness reported Table 1 . Due to the difficulties in studying the rough polystyrene substrate, five different areas for every point (15 areas analysed in total) were analysed and an example is reported in Fig. 3. 
3T3 ON POLYSTYRENE WITHOUT

Plluronics

A

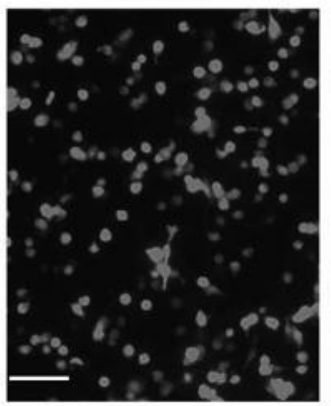

3T3 ON POLYSTYRENE WITH
Higher density FNO1

C



$\mathrm{C}_{1}$

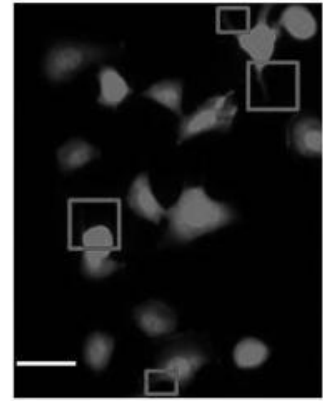

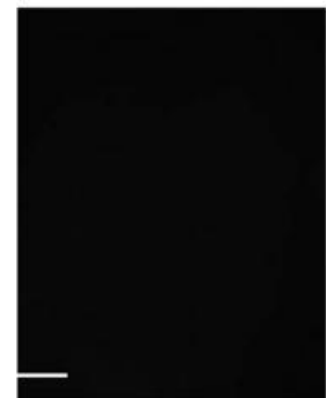

$3 T 3$ ON POLYSTYRENE WITH F127 + FN

Lower density FNO1

D

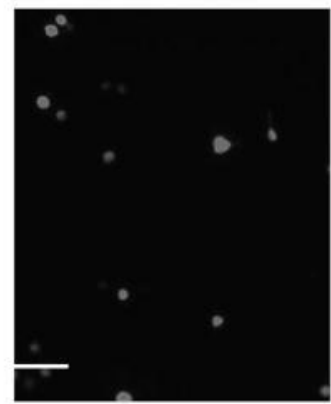

$\mathrm{D}_{1}$



E

Cell density

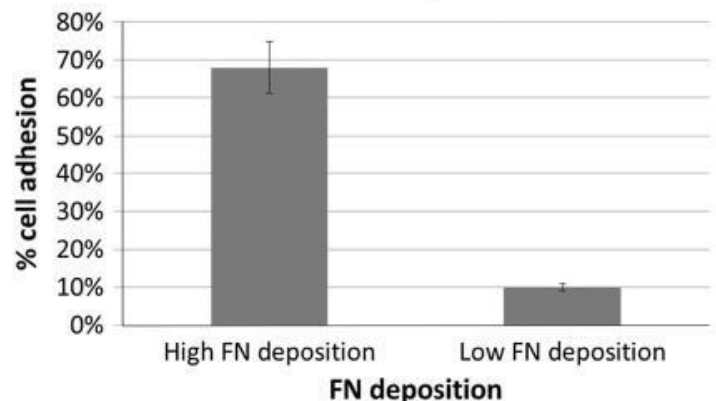

FN deposition

Fig. 5. Fluorescence microscopy images of fibroblasts adhesion acquired before and after FN and Pluronics F127 immobilization on not-TCP substrate (scale bar $100 \mathrm{tm}$ ). In figures C1 and D1 zoom (scale bar $50 \mathrm{tm}$ ) of the fibroblasts adhesion at higher and lower protein deposition from flattened and spindled profile to rounded in shape respectively. In figure E analysis of cell adhesion is reported

$$
\text { (mean } \pm \text { SD) } \text {. }
$$




\subsubsection{Fluorescence images analysis}

Fluorescence microscopy was performed using a Leica DM IRE2 Differential Interference Contrast (DIC) microscope with full stage incubation $\left(37^{\circ} \mathrm{C}, 5 \% \mathrm{CO} 2\right)$ and a Hammamatsu OrcaER monochrome camera. Fluorescence analysis was conducted using a specific filter FITC, in our case considering the excitation and emission value (535 $\mathrm{nm}$ excitation and 585 $\mathrm{nm}$ emission for Rhodamine labelled fibronectin). Time-lapse fluorescence images were acquired every $10 \mathrm{~min}$ for $24 \mathrm{~h}$.

\subsubsection{Cell adhesion and migration analysis}

Analysis of the $3 T 3$ fibroblast cells adhesion was conducted on fluorescent images before and after cell deposition on fibronectin. The Image J programme was used to evaluate the cell density on the substrate before and after the functionalisation. Three areas were analysed along the pattern and the average value reported in Fig. 5E. 3T3 fibroblast cells migration was evaluated analysing the videos collected using a time-lapse microscope every $10 \mathrm{~min}$ for $24 \mathrm{~h}$ on a Nikon live imaging station equipped with a 10x phase-contrast objective, automated $\mathrm{X}-\mathrm{Y}-\mathrm{Z}$-stage, a climate chamber and camera. Cell migration speed and directionality were analysed with the Chemotaxis and Migration tool plug-in (ibidi) for ImageJ. At least five independent analyses were considered for every point and an example of the analysis reported in Fig. 6 . The two parameters that were considered to detect the cell migration were the centre of mass (Mend), and the $X, Y$ forward migration index as reported in the literature [27-29].

\section{Results and discussion}

\subsection{Protein deposition characterisation}

As described, deposition of fluorescent protein was achieved using an electrospray technique in vacuum on silica wafer surfaces and polystyrene substrates. In Fig. 1 results of fluorescence microscopy analysis of the deposited protein is reported (using $10 \mathrm{tg} / \mathrm{mL} \mathrm{stock}$ solution). Based on fluorescence intensity, higher protein deposition was observed in the 
middle of the deposit, which decreased in the proximity of the edges. For both substrates there is a clear decrease in the intensity from the middle point to the edges of the samples.

Characterisation of the surface before and after protein immobilization was conducted using AFM imaging in tapping mode in air. Fig. 2 shows a selection of images obtained before and after protein (Rhodamine labelled fibronectin) immobilization on the silicon wafer substrate. Comparing the images before and after protein immobilization it was observed that the surface of the silicon wafer was flat, with a $R$ a roughness value of $0.4 \mathrm{~nm} \pm 0.1 \mathrm{~nm}(1 \mathrm{tm}$ by $1 \mathrm{tm}$ scan in air). After protein immobilization a uniform surface with a $R$ a value of $1.7 \mathrm{~nm} \pm$ $0.2 \mathrm{~nm}$ was observed for same sized images. This was also confirmed by the quantitative analysis of surface coverage (Table 1). This demonstrated that the nanome-tre sized droplets produced by the electrospray process created a thin protein film deposited on the silicon surface (around $30 \mathrm{~nm}$ features size).

A

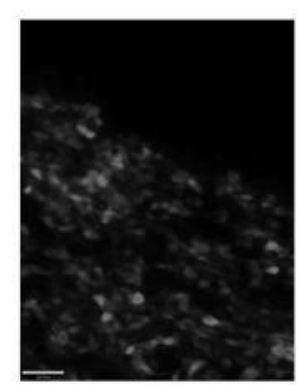

B

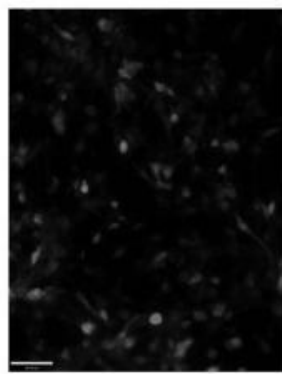

B $_{1} \quad$ Protein gradient direction

\begin{tabular}{|l|}
\hline Centre of mass $(+/-)$ \\
\hline$x=4.19 \mu \mathrm{m}$ \\
\hline$y=5.16 \mu \mathrm{m}$ \\
\hline Length $=6.65 \mu \mathrm{m}$ \\
\hline Velocity $=0.68 \mu \mathrm{m} / \mathrm{min}$ \\
\hline Directionality $=0.27$ \\
\hline Rayleigh test $<0.05$ \\
\hline
\end{tabular}
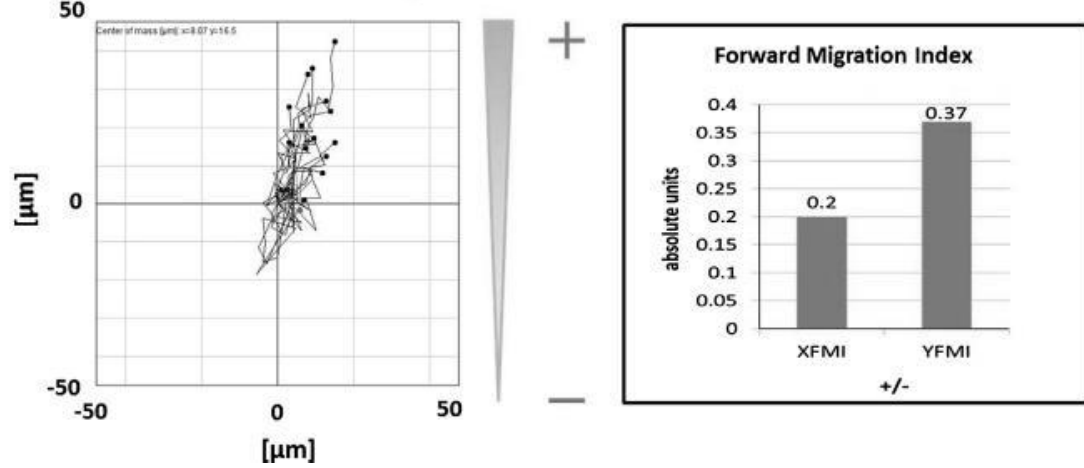

$+1-$

Fig. 6. $3 T 3$ cell migration analysis. In A and B an example of the fluorescence images acquired at time

0 and after $24 \mathrm{~h}$ respectively using time lapse microscopy. The analysis of the cell migration was conducted using Image J Chemotaxis tool IBIDI (Germany), evaluating the forward migration index as parameter to confirm the cell migration. 
The investigation of protein activity under relevant liquid conditions after electrospray deposition on silicon using a cell-adhesion based studies, is difficult because whilst this surface is normally used in surface analysis studies due to its flatness and chemical homogeneity, relative inertness and potential compatibility with sensors, it is not frequently used in cell based studies. For this reason another substrate namely the transparent polystyrene based material (not-Tissue Culture Plate substrate, not-TCP) was used in this investigation. In Fig. 1 fluorescence microscopy images on the non-TCP substrate, showing different intensity of protein deposited as for the silicon is reported. Due to the relatively rough nature of the not-TCP substrate, AFM image analysis is not so easily able to distinguish protein features. Fig. 3 shows AFM images of the non-TCP substrate both before and after the FN deposition. Analysis of the images showed a difference in roughness but clear detail of the protein distribution could not be resolved as was achieved for the silicon substrate. An increase in roughness was observed from Ra $=2.9 \pm 0.5 \mathrm{~nm}$ (before deposition) to $\mathrm{Ra}=3.5 \pm 0.3 \mathrm{~nm}$ (after fibronectin deposition). A comparable roughness parameter approach was previously used in similar work to confirm protein deposition on a similar substrate demonstrating how variations in substrate materials can influence fibronectin deposition and activity [30,31]. In Fig. 4 an analysis of the substrate profile before and after fibronectin deposition is reported showing clear differences before and after the deposition (10 analysed areas). The analysis of the profiles clearly showed that there is a change in the surface profile considering the bare substrate and after fibronectin immobilization. It is of interest to note that the measured roughness value for the lower protein surface coverage corresponding to $\mathrm{Ra}=1.8 \pm 0.2 \mathrm{~nm}$ is lower than for the bare surface. This could indicate a partial filling of "valleys" with FN molecules as was observed for the adsorption of FN molecules into valleys on titanium oxide surface [32] or the "cavities" on a poly(ethylene glycol) substrate [33]. The increased deposition of fibronectin on the substrate in the middle of the deposit (as previously confirmed from the fluorescence data analysis) led to the increased roughness observed in this area which may be related to disorder in the arrangement of adsorbed protein molecules [33,34]. 


\subsection{Assessment of fibronectin bio-functionality}

The aim of this study was to validate the use of high vacuum electrospray as a method for depositing functional fibronectin onto a material surface and to demonstrate retention of bioactivity of the deposited protein on return to a relevant liquid environment. This was evidenced by studying the deposited proteins capacity to promote cell adhesion. To assess the protein availability a cell adhesion a migration bioassay was performed.

Non-TCP substrates were used for protein immobilization and 3 T3 fibroblast cells as a suitable cell type. Initially 3T3 fibroblast cells were seeded on the fibronectin deposits using a concentration of $10^{6}$ cells in $4 \mathrm{~mL}$ of final volume. To reduce cell adhesion to the bare plastic substrate the surfactant Pluronic F127 was used to coat the non-TCP substrate. Following exposure of fibroblasts on the deposited fibronectin, cell adhesion was observed (Fig. 5). The cell adhesion was consistent with the area and density of protein deposition observed, with higher cell adhesion observed in the centre compared to the outer perimeter of the deposits, confirming the sensitivity of the cells to detect differences in protein deposition concentration. As shown in Fig. $5 \mathrm{E}$ a difference in surface coverage was observed comparing the higher and lower protein deposition from $68 \%$ to $10 \%$ of coverage. The morphology of the cells was also investigated (Fig. 5C1, D1). Morphological changes in attached cells were observed from the higher regions of $\mathrm{FN}$ deposition: more flattened and spindled profile, distributed more regularly and evenly across the not-TCP surface, to the lower FN deposition areas; more rounded in shape and distributed in a clustered and patchy fashion.

To assess the specificity of the response to the deposition of fibronectin, further adhesion studies were conducted using fibronectin and Pluronics F127 functionalized surfaces. Fluorescent microscopy analysis revealed a complete covering of cells on the fibronectin coated surface, with no cell adhesion on Pluronic F127. The concentration of surfactant used in the cell investigation ( $3 \% \mathrm{w} / \mathrm{v})$ was optimal to avoid cell adhesion but weak enough to permit protein deposition. Cell migration in the direction of the higher protein deposition was observed after $24 \mathrm{~h}$ (Fig. 6) confirming the ability of the cells to detect and react to 
chemo-attractant signals on the substrate. This behaviour is related to the ability of fibronectin to change its native conformation when absorbed on the substrate, influencing the cell adhesion and spreading [35]. The role of the RGD sequence within fibronectin in fibroblast adhesion and migration is well known [36], and it is reasonable to propose that the presence of a higher fibronectin deposition can increase the chance to find more RGD complexes on the surface favouring cell adhesion at that location. It should be noted, however, that cellular attachment to fibronectin can occur through a variety of mechanisms, involving integrins, syndecans, and other receptor systems. Further studies are required to elucidate the mechanism of attachment.

\section{Conclusions}

The aim of this study was to validate the use of electrospray in vacuum as a method for depositing fibronectin onto a material surface and to demonstrate that on return to a liquid environment protein functionality was retained. The deposition of fibronectin was characterised using atomic force microscopy and fluorescence microscopy. This data demonstrated changes in protein deposition and surface coverage on the silicon wafer and not-TCP substrates. Images of the fibronectin deposition on the silica wafer demonstrated nanoscale features consistent with the protein with an increased concentration of fibronectin in the centre of the deposition spot compared to the edges. AFM analysis of the non-TCP (polystyrene) substrate revealed a changed profile before and after protein deposition confirming the immobilization of protein on the substrate as reported. To assess the bioavailability of the protein on the substrate, a biological assay was performed assessing the cell adhesion and cell shape before and after FN deposition. The data collected confirmed the ability of the fibroblasts to recognise $F N$ on the substrate in the right conformation to permit cell adhesion. A migration in the direction of the higher deposition was also observed after $48 \mathrm{~h}$ confirming the presence of a chemo-attractant signal.

Previous studies $[30,32,33]$ have demonstrated that proteins may be deposited with functional integrity using various methods to maintain protein stability. In this study the 
assessment of protein function has been extended by studying the cellular response to electrospray deposits. We have shown that high vacuum electrospray deposition can be used to produce surface that retain their biologically activity in liquid for fibronectin deposits on substrates. The ability to deposit proteins in vacuum environment opens new frontiers in the potential in situ use of a range of analytical techniques that can probe the interaction geometry, electronic structure and self-assembly at the atomic scale such photoelectron spectroscopy and low temperature scanning tunnelling microscopy. Such studies would improve our understanding of the protein at a solid interface. In addition this work it paves the way for biological molecules to be incorporated into the fabrication of semiconductor devices such as biosensors without breaking vacuum, and that these molecules will retain their biological functionality. Moreover, this approach could offer precise control over the surface coverage of functional biomolecules from sub-monolayer to multilayer films for the formation of concentration gradients and related applications.

\section{References}

[1] H. Park, C. Cannizzaro, G. Vunjak, R. Langer, C.A. Vacanti, O.C. Farokhzad, Tissue Eng. 2007 (1867) 13, http://dx.doi.org/10.1089/ten.2006.0198.

[2] S.J. Hollister, Nat. Mater. 4 (2005) 518, http://dx.doi.org/10.1038/nmat1421.

[3] R. Ruoslahti, M.D. Pierschbacher, Science 238 (1987) 491, http://dx.doi.org/10.1126/science.2821619.

[4] G.M. Edelman, Science 219,(1983) 450, http://dx.doi.org/10.1126/science.6823544.

[5] T.A. Haas, E.F. Plow, Curr. Opin. Cell Biol. 6 (1994) 662, http://dx.doi.org/ 10.1016/0955674(94)90091-4.

[6] H.A. Stone, S. Kim, Al. Ch. E. J. 47 (2001) 1250, http://dx.doi.org/10.1002/ aic.690470602.

[7] T.M. Squires, S.R. Quake, Rev. Mod. Phys. 77 (2005) 977, http://dx.doi.org/10.1103/RevModPhys.77.977.

[8] M. Mrksich, L.E. Dike, J. Tien, D.E. Ingber, G.M. Whitesides, Exp. Cell Res. 235 (1997) 305, http://dx.doi.org/10.1006/excr.1997.3668.

[9] P.G. Campbell, E.D. Miller, G.W. Fisher, L.M. Walker, L.E. Weiss, Biomaterials 26 (2005) 6762, http://dx.doi.org/10.1016/j.biomaterials.2005.04.032. 
[10] J.U. Park, M. Hardy, S.J. Kang, K. Barton, K. Adair, D.K. Mukhopadhyay, C.J. Lee, M.S. Strano, A.G. Alleyne, J.G. Georgiadis, P.M. Ferreira, Nat. Mater. 6 (2007) 782, http://dx.doi.org/10.1038/nmat1974.

[11] M.D. Paine, M.S. Alexander, K.L. Smith, J.P. Stark, J. Aerosol Sci. 38 (2007) 315, http://dx.doi.org/10.1016/j.jaerosci.2006.12.004.

[12] M.A. Reed, C. Zhou, C.J. Muller, T.P. Burgin, J.M. Tour, Science 278 (1997) 252, http://dx.doi.org/10.1126/science.278.5336.

[13] Y. Cui, Q. Wei, H. Park, C.M. Lieber, Science 293 (2001) 1289, http://dx.doi.org/10.1126/science.10672711.

[14] J.B. Fenn, M. Mann, C.K. Meng, F.S. Wong, C.M. Whitehouse, Science 64 (1989) 4926, http://dx.doi.org/10.1126/science.2675315.

[15] R.B. Cole, J. Mass Spectrom. 35 (2000) 763, http://dx.doi.org/10.1002/1096-9888(200007).

[16] V.N. Morozova, T.Y. Morozova, Anal. Chem. 71 (1999) 3110, http://dx.doi.org/10.1021/ac9808775.

[17] V.N. Morozova, T.Y. Morozova, N.R. Kallenbach, Int. J. Mass Spectrom. 178 (1998) 143, http://dx.doi.org/10.1016/S1387-3806(98)14083-6.

[18] L.Y. Yeo, Z. Gagnon, H. Chang, Biomaterials 26 (2005) 6122, http://dx.doi.org/10.1016/j.biomaterials.2005.03.033

[19] S.N. Jayasinghe, M.J. Edirisinghe, J. Mater. Sci. Lett. 22 (2003) 1443, http:// dx.doi.org/10.1007/s10019-003-0228-4.

[20] B. Lee, J.W. Kim, K. Ishimoto, Y. Yamagata, A. Tanioka, T. Nagamune, J. Chem. Eng. Jpn. 36 (2003) 1370, http://dx.doi.org/10.1252/jcej.36.1370.

[21] S. Rauschenbach, L.F. Stadler, E. Lunedei, N. Malinowski, S. Koltsov, G. Costantini, K. Kern, Small 4 (2006) 540, http://dx.doi.org/10.1002/ smll.200500479.

[22] Z. Deng, N. Thontasen, N. Malinowski, G. Rinke, L. Harnau, S. Rauschenbach, K. Kern, Nano Lett. 12 (5) (2012) 2452-2458, http://dx.doi.org/10.1021/ nl3005385.

[23] M.C. O'Sullivan, J.K. Sprafke, D.V. Kondratuk, C. Rinfray, T.D.W. Claridge, A. Saywell, M.O. Blunt, J.N. O’Shea, P.H. Beton, M. Malfois, H.L. Anderson, Nature 72 (2011) 469, http://dx.doi.org/10.1038/nature09683.

[24] K. Handrup, V.J. Richards, M. Weston, N.R. Champness, J.N. O’Shea, J. Chem. Phys. 139 (2013) 154708, http://dx.doi.org/10.1063/1.4825382. 
[25] A. Gibson, R.G. Temperton, K. Handrup, M. Weston, L.C. Mayor, J.N. O’Shea, J. Chem. Phys. 140 (2014) 234708, http://dx.doi.org/10.1063/1.4882867.

[26] J.E. Dixon, E. Dick, D. Rajamohan, K.M. Shakesheff, C. Denning, Mol. Ther. 19 (2011) 1695, http://dx.doi.org/10.1038/mt.2011.125.

[27] P. Suraneni, B. Rubinstein, J.R. Unruh, M. Durnin, D. Hanein, R. Li, J. Cell Biol. 2 (2012) 251, http://dx.doi.org/10.1083/jcb.201112113.

[28] C.O. Morgner, P. Reichardt, M. Chopin, S. Braungart, C. Wahren, M. Gunzer, R. Jessberger, J. Immunol. 186 (2011) 5355, http://dx.doi.org/10.4049/ jimmunol.1003461.

[29] P.J. Hanley, Y. Xu, M. Kronlage, K. Grobe, P. Schön, J. Song, L. Sorokin, A. Schwab, M. Bähler, PNAS 107 (2010) 12150, http://dx.doi.org/10.1073/ pnas.0911986107.

[30] H.M. Kowalczynska, R. Kolos, M.N. Wyrzykowska, J. Dobovsky, D. Elbaum, A. Szczepankiewicz, J. Kaminski, J. Biomed. Mater. Res. 01 (2009) 1239, http:// dx.doi.org/10.1002/jbm.a.32473.

[31] N.B. Guerra, C.G. Garcıa, V. Llopis, J.C.R. Hernandez, D. Mortal, S. Rico, S.M. Sanchez, Soft Matter 6 (2010) 4847, http://dx.doi.org/10.1039/COSM00345J.

[32] S.R. Sousa, M.M. Bras, P. Moradas-Ferreira, M.A. Barbosa, Langmuir 23 (2007) 7046, http://dx.doi.org/10.1021/la062956e.

[33] E. Tziampazis, J. Kohn, P. Moghe, Biomaterials 21 (2000) 511, http://dx.doi.org/ 10.1016/S01429612(99)00212-4.

[34] M. Bergkvist, J. Carlsson, S. Oscarsson, J. Biomed. Mater. Res. A 64 (2003) 349, http://dx.doi.org/10.1002/jbm.a.10423.

[35] T.P. Ugarova, C. Zamarron, Y. Veklich, R.D. Bowditch, M.H. Ginsberg, J.W. Weisel, E.F. Plow, Biochemistry 34 (1995) 4457, http://dx.doi.org/10.1021/ bi00013a039.

[36] R.A.F. Clark, A.J. Qiang, D. Greiling, A. Khan, J.E. Schwarzbauer, J. Invest. Dermatol. 121 (2003) 4, http://dx.doi.org/10.1046/j.1523-1747.2003.12484.x 